Cardiopulmonary

Support

and Physiology

\title{
Delayed detection of motor pathway dysfunction after selective reduction of thoracic spinal cord blood flow in pigs
}

\author{
Jeroen Lips, BS ${ }^{\mathrm{a}}$ \\ Peter de Haan, MD, PhDa \\ Gerrit J. Bouma, MD, PhD \\ Michael J. Jacobs, MD, PhDc \\ Cor J. Kalkman, MD, PhD ${ }^{d}$
}

From the Department of Anesthesiology, ${ }^{\mathrm{a}}$ Department of Neurosurgery, ${ }^{\mathrm{b}}$ Academic Medical Center, University of Amsterdam, Amsterdam, The Netherlands; Department of Surgery, ${ }^{\mathrm{c}}$ University Hospital Maastricht, University of Maastricht, Maastricht, The Netherlands; and Department of Anesthesiology, ${ }^{\mathrm{d}}$ University Hospital Utrecht, The Netherlands.

Mr Lips is supported by the Dutch Heart Foundation (Den Haag, The Netherlands; grant 97-193). This study was funded in part by the Departments of Anesthesiology and Experimental Surgery, University of Amsterdam (The Netherlands).

Received for publication April 23, 2001; revisions requested June 11, 2001; revisions received June 18, 2001; accepted for publication June 20, 2001.

Address for reprints: Jeroen Lips, Department of Anesthesiology (H1-115), Academic Medical Center, University of Amsterdam, Meibergdreef 9, 1105 AZ Amsterdam, The Netherlands (E-mail: j.lips@amc.uva.nl).

J Thorac Cardiovasc Surg 2002;123:531-8

Copyright @ 2002 by The American Association for Thoracic Surgery

0022-5223/2002 $\$ 35.00+0 \quad \mathbf{1 2 / 1 / 1 1 8 0 4 8}$

doi:10.1067/mtc.2002.118048
Objective: Clinical monitoring of myogenic motor evoked potentials to transcranial stimulation provides rapid evaluation of motor-pathway function during surgical procedures in which spinal cord ischemia can occur. However, a severe reduction of spinal cord blood flow that remains confined to the thoracic spinal cord might render ischemic only the descending axons of the corticospinal pathway. In this situation lower-limb motor evoked potentials could respond relatively late compared with a similar spinal cord blood flow reduction of the lumbar spinal cord that renders predominantly motoneurons ischemic.

Methods: Selective thoracic and lumbar spinal cord ischemia was induced by sequential clamping of segmental arteries during continuous assessment of laserDoppler spinal cord blood flow at the thoracic and lumbar spinal cord. Myogenic motor evoked potentials were recorded from the upper and lower limbs. The time to loss of motor evoked potentials was compared $(\mathrm{n}=11)$ during reduction of laserDoppler spinal cord blood flow below 25\% of baseline (ischemic segment), and flow was maintained at greater than $75 \%$ of baseline in the nonischemic segment, both during thoracic and lumbar spinal cord ischemia.

Results: Average laser-Doppler spinal cord blood flow in the ischemic segment was similar during thoracic $(26 \% \pm 15 \%[ \pm \mathrm{SD}])$ and lumbar $(26 \% \pm 16 \%)$ ischemia, whereas normal flow was maintained in the nonischemic segment. The time to motor evoked potentials loss was considerably longer after thoracic spinal cord ischemia (15 \pm 11 minutes) than after lumbar spinal cord ischemia $(3 \pm 2$ minutes, $P<.005)$.

Conclusion: In this experimental model of selective spinal cord ischemia, a severe reduction of lumbar spinal cord blood flow results in rapid loss of myogenic motor evoked potentials, whereas a similar blood flow reduction in the thoracic spinal cord results in relatively slow loss of motor evoked potentials. The effectiveness of motor evoked potentials to rapidly assess spinal cord integrity might be limited when spinal cord ischemia is confined to the thoracic segments.

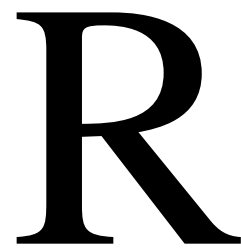

apid detection of spinal cord transmission failure can guide interventions aimed at maintaining spinal cord blood flow (SCBF) in surgical procedures that carry a risk of spinal cord ischemia (SCI). Either sensory or motor pathways can be monitored. Intraoperative monitoring of the spinal cord dorsal columns with only somatosensory evoked potentials may result in false-positive results and 
delayed detection of SCBF reduction. ${ }^{1,2}$ Myogenic transcranial motor evoked potentials (tcMEP) allow assessment of the integrity of motor tract conduction. ${ }^{3,4}$ They are lost almost instantaneously after crossclamping of the thoracic aorta, ${ }^{5,6}$ probably as a result of synaptic failure in the anterior horn. However, with this technique, the signal traverses at least 3 synapses (motor cortex, anterior horn, and neuromuscular junction), and it is not possible to distinguish between ischemia of gray matter and white matter. Synaptic conduction block precedes axonal transmission failure during severe reduction of $\mathrm{SCBF}^{7}$ or hypoxia, ${ }^{8}$ and both structures are vulnerable to ischemia. ${ }^{9-11}$ Therefore a critical reduction of SCBF that remains confined to the thoracic spinal cord might render ischemic only the descending axons in the corticospinal pathway of tcMEP. This could delay the time needed for tcMEP to decrease below the ischemic threshold compared with a similar SCBF reduction of the lumbar spinal cord, where the anterior horn motoneurons are located. In this situation there is a definite risk of false-negative monitoring results. The purpose of this study was to compare lower-limb recorded tcMEP response times in a porcine model of selective reduction of lumbar and thoracic SCBF.

\section{Materials and Methods}

Animal care and experimental procedures were performed in compliance with The National Guidelines for Care of Laboratory Animals in The Netherlands. The study protocol was approved by the Animal Research Committee of the Academic Hospital at the University of Amsterdam, The Netherlands. Eleven pigs, weighing $61 \pm 5 \mathrm{~kg}$, were included in the study.

\section{Anesthesia}

Premedication consisted of $15 \mathrm{mg} / \mathrm{kg}$ ketamine administered intramuscularly. Anesthesia was induced with inhalation by mask of $2.0 \%$ isoflurane in a mixture of $50 \%$ oxygen in air. Two intravenous catheters (18 gauge) were placed in an ear vein, and normal saline solution was infused at a rate of $15 \mathrm{~mL} \cdot \mathrm{kg}^{-1} \cdot \mathrm{h}^{-1}$. After induction of anesthesia, $15 \mu \mathrm{g} / \mathrm{kg}$ sufentanil and $2 \mu \mathrm{g} / \mathrm{kg}$ clonidine was given intravenously, isoflurane was discontinued, and anesthesia was maintained with a continuous infusion of ketamine (15 $\left.\mathrm{mg} \cdot \mathrm{kg}^{-1} \cdot \mathrm{h}^{-1}\right)$, sufentanil $\left(5 \mu \mathrm{g} \cdot \mathrm{kg}^{-1} \cdot \mathrm{h}^{-1}\right)$, and clonidine $(1 \mu \mathrm{g}$ $\left.\cdot \mathrm{kg}^{-1} \cdot \mathrm{h}^{-1}\right)$. The tracheas were intubated, and animals were ventilated by intermittent positive-pressure ventilation. End-tidal carbon dioxide concentration was measured with a mainstream capnograph (Hewlett-Packard, Boebingen, Germany), and $\mathrm{PaCO}_{2}$ was maintained between 36 and $40 \mathrm{~mm} \mathrm{Hg}$. Mean arterial pressure was maintained between 50 and $70 \mathrm{~mm} \mathrm{Hg}$. Adequacy of ventilation was confirmed by means of blood gas analysis at $37^{\circ} \mathrm{C}$. The level of neuromuscular blockade was monitored electromyographically with a Datex Relaxograph (Datex-Ohmeda, Helsinki, Finland) placed at the animal's wrist equivalent after stimulation of the median nerve. A closed-loop infusion system with pancuronium was used to maintain $40 \%$ relaxation, as referenced to the control situation. Arterial blood pressure and central venous pres- sure were measured from catheters placed in the right femoral artery and the left cephalic vein, respectively. Oxygen saturation was continuously assessed with pulse oximetry. Nasopharyngeal temperature was monitored and kept at $36^{\circ} \mathrm{C}$ by means of a heating lamp. Urinary output was measured throughout the experiment. Before the induction of ischemia, arterial $\mathrm{pH}, \mathrm{PaO}_{2}, \mathrm{PaCO}_{2}$, hemoglobin concentration, and hematocrit level were measured.

\section{Motor Evoked Potential Recording}

tcMEP stimuli were applied with a transcranial electrical stimulator (Digitimer D 185 cortical stimulator, Welwyn Garden City, United Kingdom) through 4 needle electrodes attached to the scalp. A train of 4 pulses with an interstimulus interval of $2 \mathrm{~ms}$ was distributed over the motor cortex through an anode located at the occiput and 3 interconnected cathodes placed behind the ears and in the soft palate. Compound muscle action potentials were recorded bilaterally from the skin over the upper-limb triceps muscles and over the lower-limb quadriceps muscles by adhesive gel $\mathrm{Ag} / \mathrm{AgCl}$ electrodes. The signals were amplified 5000 to 20,000 times (adjusted to obtain maximum vertical resolution) and filtered between 30 and $1500 \mathrm{~Hz}$ with a 3T PS-800 biologic amplifier (Twente Technology Transfer, Twente, The Netherlands). Stimulus intensity was adjusted to acquire maximal responses, and recording was performed $10 \%$ above the level that obtained maximal amplitude. Amplitude of the compound muscle action potentials was defined as the peak-to-peak distance in microvolts. A reduction of tcMEP amplitude on the muscle groups monitored to less than $25 \%$ of the baseline value was considered an indication of ischemic spinal cord dysfunction. Baseline tcMEP were obtained during the surgical procedure by averaging 10 consecutive responses before the start of SCI induction. During the ischemic manipulations, tcMEP were acquired every minute. Responses were displayed and stored on a Macintosh Quadra computer (Apple Computer, Cupertino, Calif), with 12-bit A/D conversion and acquisition software written in the LabVIEW programming environment (National Instruments, Austin, Tex). ${ }^{12}$

\section{Operative Procedure}

Animals were placed in the right decubitus position. The thoracoabdominal aorta, the segmental arteries, and the medial sacral artery were exposed by way of a left-sided thoracophrenic laparotomy. The arterial truncus giving rise to the left subclavian and vertebral arteries was exposed. The group of vessels recruited for the induction of SCI consisted of all segmental arteries, the left vertebral artery, and the sacral artery. After that, the thorax and pelvis were rotated for the removal of vertebral bone. At the end of the experiment, the interior of the aorta was inspected to determine whether all lumbar and intercostal segmental arteries had been identified.

\section{Laser-Doppler Flowmetry}

So that real-time microcirculatory changes in the spinal cord could be assessed after the clamping of segmental arteries, the dura over the spinal cord was exposed after drilling 2 holes $(2 \times 2 \mathrm{~cm})$ in the ventral aspect of vertebral bodies Th10 and L5. The tips of 2 separate fiberoptic laser Doppler flowmetry (LDF) probes (model 408; Perimed, Stockholm, Sweden) were placed in contact with 


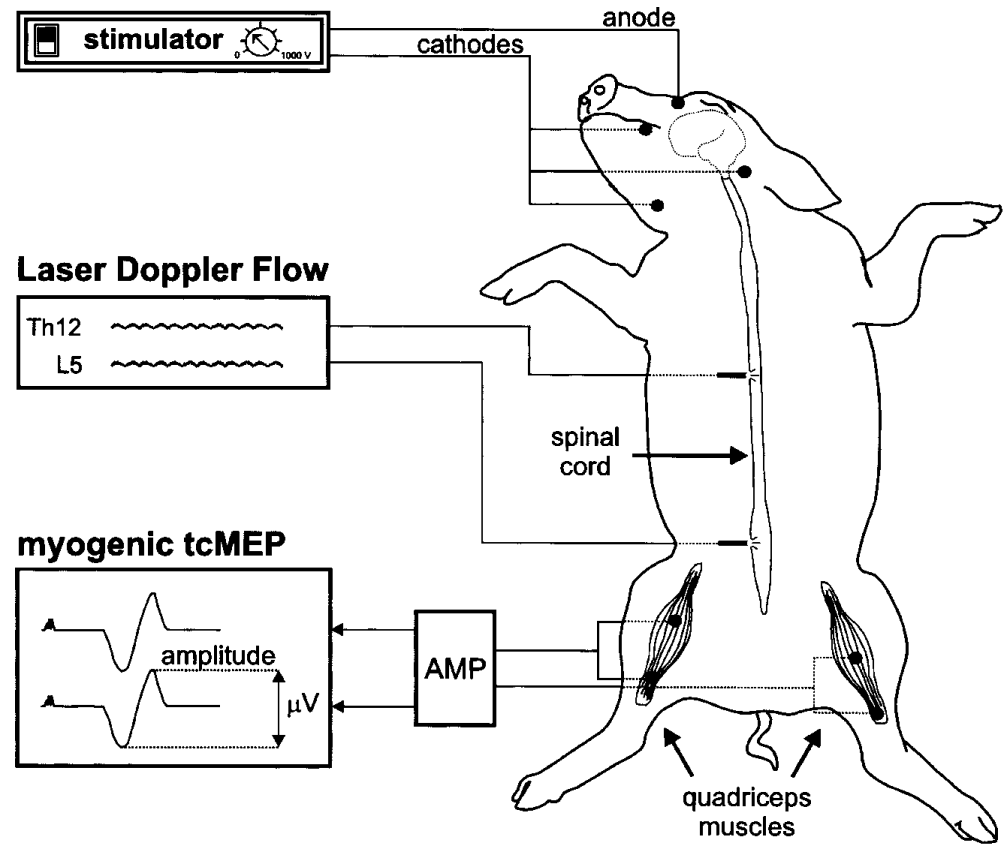

Figure 1. Schematic representation of tcMEP and LDF recording.

the intact dura of a spinal cord area devoid of macroscopically visible blood vessels and connected to a laser-Doppler flowmeter (Periflux 4001, Perimed). The area surrounding the interface between the probe and the dura was cleaned to optimize signal transduction. Valid flow signals were defined as having arterial pulsations. The probes were fixated in a riding position over the spinal cord, and special care was taken to avoid compression of spinal cord tissue. Output signals were collected continuously throughout the experiment and averaged every 0.5 seconds. Two periods of 15 minutes each were taken for stabilization and measurement of baseline LDF values, respectively, after which induction of SCI was started immediately. Movement artifacts caused by transcranial stimulation were filtered out during off-line analysis, and the signals were corrected for their biologic offset values (as collected after the animals were killed).

\section{Experimental Design}

Figure 1 shows the experimental setup. Fifteen minutes before the induction of SCI, baseline values for tcMEP and SCBF were obtained. Animals were randomized to undergo selective lumbar SCI, followed by thoracic SCI $(n=5)$, or selective thoracic SCI, followed by lumbar SCI $(n=6)$. To produce selective thoracic SCI, segmental arteries were clamped in a cranial-to-caudal direction. Segmental arteries were clamped in a caudal-to-cranial direction to produce selective lumbar SCI. The total number of clamped arteries was dependent on the SCBF reduction attained in each of the 2 spinal cord sections. Previous studies that measured SCBF after occlusion of the thoracic aorta with microspheres ${ }^{13}$ or LDF ${ }^{14}$ showed that a $75 \%$ reduction in SCBF abolished evoked potentials. In the present study the SCBF levels in the respective spinal cord sections were adjusted by clamping and unclamping of segmental arteries until SCBF levels obtained were below $25 \%$ of baseline for the ischemic spinal cord section, while SCBF remained above $75 \%$ of baseline in the nonischemic spinal cord section. Because it is not always possible to produce such a clear blood-flow contrast between adjacent segments, priority was given to maintaining normal flow in the nonischemic segment, even when the target in the ischemic segment ( $<25 \%$ of baseline value) was not reached. Therefore, in some animals the SCBF level of the ischemic segment was allowed to remain above $25 \%$ of the baseline value. After loss of the lower-limb tcMEP signal (tcMEP amplitude $<25 \%$ of baseline), all clamps were released. Before the start of the alternative ischemic episode, a stabilization period of 15 minutes was taken.

\section{Statistical Analysis}

Hemodynamic data, blood gases, weight, and temperatures are expressed as means \pm SD after grouping according to the primary ischemic event (lumbar or thoracic). tcMEP are expressed as medians and 10th to 90th percentiles. The physiologic variables were analyzed with 1-way analysis of variance, and when significant differences were identified, Student $t$ tests for intergroup comparisons with appropriate corrections for multiple comparisons were carried out. The interval between induction of selective SCI and loss of lumbar tcMEP was compared with an unpaired $t$ test.

\section{Results}

Preischemic physiologic parameters, including, $\mathrm{pH}, \mathrm{PaO}_{2}$, hematocrit, hemoglobin, and esophageal temperature, were 
TABLE 1. Physiologic parameters

\begin{tabular}{lcccccc}
\hline First episode & $\mathbf{p H}$ & $\mathbf{P a c o}_{\mathbf{2}}(\mathbf{m m ~ H g})$ & $\mathbf{P a o}_{\mathbf{2}}(\mathbf{m m ~ H g})$ & Hematocrit $(\%)$ & Hemoglobin $(\mathbf{g} / \mathbf{d L})$ & Temperature $\left({ }^{\circ} \mathbf{C}\right)$ \\
\hline Lumbar SCI $(\mathrm{n}=5)$ & $7.44 \pm 0.06$ & $37.4 \pm 5.6$ & $191.2 \pm 47.2$ & $33.3 \pm 3.6$ & $10.8 \pm 1.2$ & $35.7 \pm 1.7$ \\
Thoracic SCl $(\mathrm{n}=4)$ & $7.47 \pm 0.01$ & $37.2 \pm 3.4$ & $253.9 \pm 57.6$ & $30.8 \pm 5.0$ & $10.0 \pm 1.7$ & $35.6 \pm 2.0$ \\
\hline
\end{tabular}

All values are means \pm SD.

TABLE 2. tcMEP responses and SCBF after grouping according to first ischemic event

\begin{tabular}{lcc}
\hline & Thoracic first & Lumbar first \\
\hline $\begin{array}{c}\text { Time to tcMEP loss (min) } \\
\text { during lumbar SCI }\end{array}$ & $2.9 \pm 1.8$ & $2.4 \pm 1.5$ \\
$\begin{array}{c}\text { Time to tcMEP loss (min) } \\
\quad \text { during thoracic SCI }\end{array}$ & $13.7 \pm 3.3$ & $16.6 \pm 15.7$ \\
SCBF (\%) during lumbar SCI & & \\
L5 & $17.5 \pm 9.6$ & $32.5 \pm 17.5$ \\
Th10 & $92.5 \pm 16.4$ & $94.7 \pm 17.5$ \\
SCBF (\%) during lumbar SCI & & \\
L5 & $85.2 \pm 13.1$ & $94.0 \pm 20.2$ \\
Th10 & $21.8 \pm 11.5$ & $28.9 \pm 17.8$ \\
\hline
\end{tabular}

All values are means \pm SD. Time to tcMEP loss is the time between the onset of flow reduction and tcMEP amplitude reduction of more than $75 \%$.

similar for animals that underwent thoracic SCI first compared with animals that underwent lumbar SCI first (Table 1). The medial sacral artery, 5 to 6 lumbar segmental arteries, 7 to 9 intercostal segmental arteries, and the left vertebral artery could be identified in all animals. To obtain a selective reduction of lumbar SCBF, $9 \pm 3$ (mean \pm SD) arteries had to be clamped in a caudal-to-cranial direction (starting from the medial sacral artery). It was necessary to clamp $12 \pm 1$ arteries in a cranial-to-caudal direction (starting from the left vertebral artery) to provide selective reduction of thoracic SCBF. Figure 2 shows representative tcMEP and laser-Doppler SCBF recordings in one experiment.

\section{Laser-Doppler Flowmetry}

Physiologic laser-Doppler SCBF signals were obtained in all animals. In 3 animals the LDF probes had to be repositioned during baseline recordings because of low or very high light output. In the 15-minute period preceding ischemic manipulations, average deviation of laser-Doppler SCBF values from baseline was 7\% and 9\% for the thoracic and lumbar level, respectively, before thoracic SCI. Preceding lumbar SCI, the average deviation of laserDoppler SCBF values was 9\% and 10\% for the thoracic and lumbar level, respectively. Individual values of laserDoppler SCBF and times until loss of lower-limb tcMEP signals are shown in Figure 3. The average relative laser-
Doppler SCBF level of the ischemic spinal cord segment during lumbar SCI $(26 \% \pm 16 \%)$ and thoracic SCI $(26 \% \pm$ $15 \%$ ) was the same. In 2 animals during lumbar SCI and in 1 during thoracic SCI, laser-Doppler SCBF in the ischemic spinal cord segment could not be reduced to less than 50\% of baseline value (Figure 3). SCBF in the nonischemic segment was maintained during lumbar $(90 \% \pm 17 \%)$ and thoracic $(94 \% \pm 16 \%)$ SCI. No differences in mean arterial pressure were detected during lumbar SCI $(52 \pm 7 \mathrm{~mm} \mathrm{Hg})$ and thoracic SCI $(50 \pm 6 \mathrm{~mm} \mathrm{Hg})$. The time needed to achieve relevant laser-Doppler SCBF differences between the ischemic and the nonischemic segment during lumbar (5 \pm 5 minutes) or thoracic ( $7 \pm 6$ minutes) SCI was similar. No differences in reductions of SCBF were obtained in the ischemic and nonischemic segment after grouping the animals according to the first ischemic event (thoracic or lumbar, Table 2).

\section{Motor Evoked Potentials}

Reproducible tcMEP were obtained in all animals. The median amplitude of the lower-limb tcMEP before ischemic manipulations was $804 \mu \mathrm{V}(81-3114 \mu \mathrm{V}, 10$ th-90th percentile) and $775 \mu \mathrm{V}$ (147-2449 $\mu \mathrm{V})$ for animals first undergoing lumbar and thoracic SCI, respectively. Complete disappearance of the lower-limb tcMEP was observed in all animals, during both selective thoracic SCI and selective lumbar SCI. The time to loss of tcMEP signals (amplitude $<25 \%$ of baseline value) was much shorter with lumbar SCI ( $3 \pm 2$ minutes) than during thoracic SCI $(15 \pm 11$ minutes, $P<.005)$.

There were no differences in time to tcMEP loss between animals that first underwent reduction of thoracic SCBF compared with animals that first underwent reduction of lumbar SCBF, both during lumbar SCI and thoracic SCI (Table 2).

\section{Discussion}

In the present study we selectively reduced SCBF in either the thoracic or lumbar segments, as evidenced with LDF measurements. After severe reduction of lumbar SCBF, lower-limb responses to transcranial stimulation were abolished within 3 minutes, but a similar SCBF reduction in the thoracic spinal cord required 15 minutes for loss of tcMEP. These data suggest that myogenic tcMEP are not fast detectors of SCI that is confined to the thoracic spinal cord. 

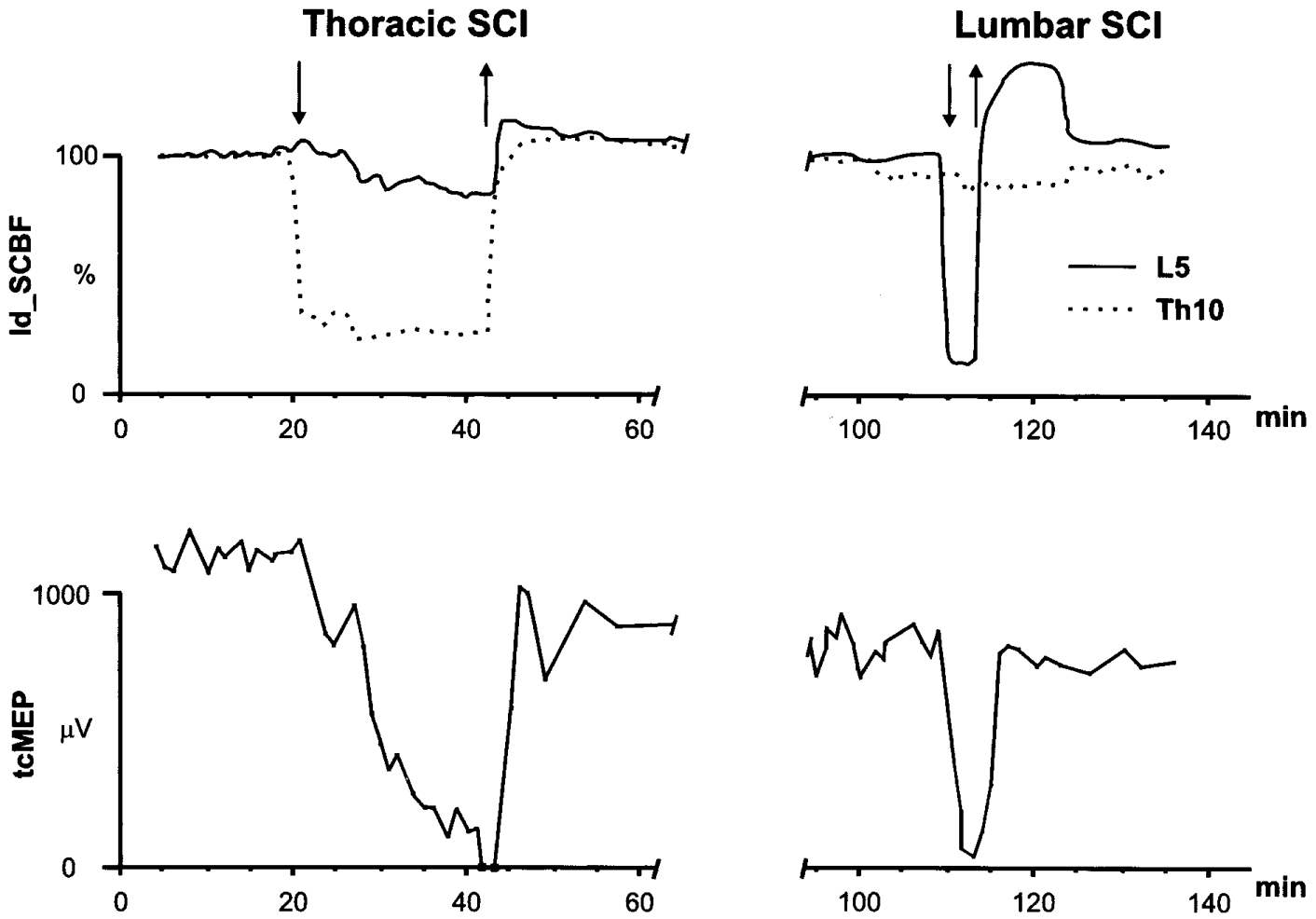

Figure 2. tcMEP amplitudes and relative LDF values during thoracic and lumbar SCI in one animal are shown. Downward vertical arrows indicate time points (22 and 109 minutes, respectively) at which flow values reached the desired thresholds ( $<25 \%$ for the ischemic spinal cord segment and $>75 \%$ for the nonischemic spinal cord segment) to induce selective thoracic or lumbar SCI. Note gradual reduction of tcMEP amplitude after thoracic SCI compared with rapid tcMEP loss after lumbar SCI. Upward vertical arrows indicate time points (42 and 112 minutes, respectively) at which all arterial clamps were released. $L 5$, Relative flow values at fifth lumbar vertebral level; Th10, relative flow values at 10th thoracic vertebral level.

We opted to reduce SCBF by means of sequential clamping of segmental arteries. Compared with aortic clamping, this model minimizes the risk of false-positive responses caused by ischemia of the peripheral nerve and muscles and avoids major cardiovascular changes during aortic occlusion and the subsequent reperfusion period. The spinal cord blood supply of the pig resembles that of human subjects because it comprises a plurisegmental segmental artery supply of a continuous anterior spinal artery. ${ }^{15,16}$ The critical region of SCBF is located in the lower thoracic region, facilitating flow in the lumbar region because of a large decrease in diameter of the anterior spinal artery in the cranial direction and the presence of extensive collateral circulation in the lumbar spinal cord. ${ }^{15,16}$ Animals were randomized to undergo reduction of thoracic SCBF or reduction of lumbar SCBF as the primary ischemic event to avoid the possible confounding effect of the first SCBF reduction on the second SCBF reduction (Table 2). We clamped or unclamped segmental arteries to reach and maintain the target SCBF levels in the ischemic and nonis- chemic spinal cord segments. The design of this study required a gradient between the ischemic and nonischemic segments. In 3 animals, however, we were unable to decrease SCBF in the ischemic segment without compromising flow in the adjacent (nonischemic) segment. In these animals we accepted a flow reduction in the ischemic segment that was less than $75 \%$ of the target reduction. Interestingly, in 2 animals (Figure 3 ) a moderate reduction of lumbar laser-Doppler SCBF resulted in a relatively fast loss of tcMEP signals, suggesting that the laser-Doppler SCBF threshold for transmission block in the lumbar spinal cord might be considerably higher than the SCBF levels commonly associated with ischemic dysfunction.

\section{Laser-Doppler Flowmetry}

We measured SCBF with LDF probes placed on the ventral aspect of the spinal cord. This allowed estimation of SCBF in the spinal cord area supplied by the anterior spinal artery. In contrast to other methods of measuring SCBF, the high temporal resolution of LDF makes it possible to detect rapid 
Lumbar SCI
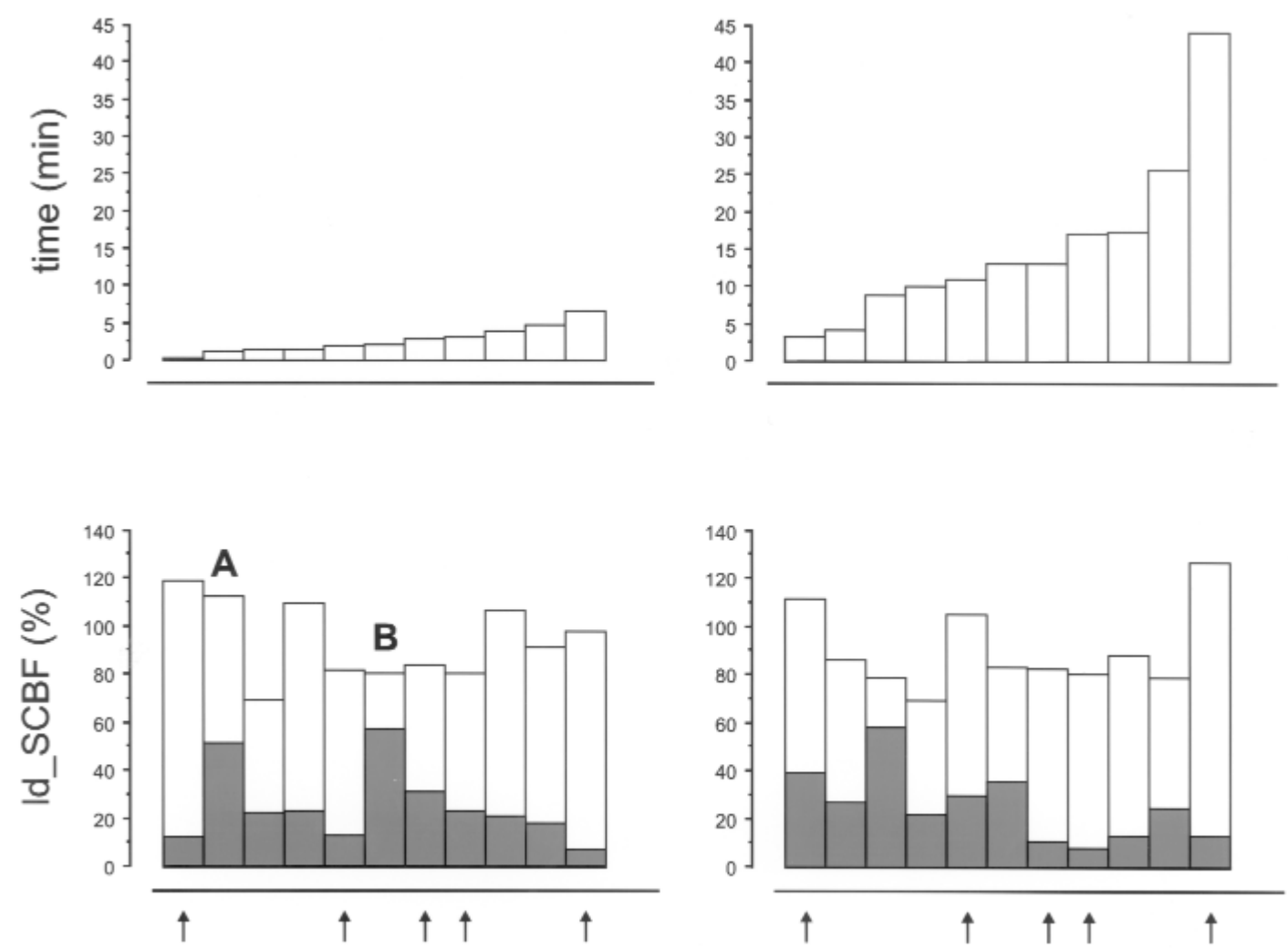

Thoracic SCI

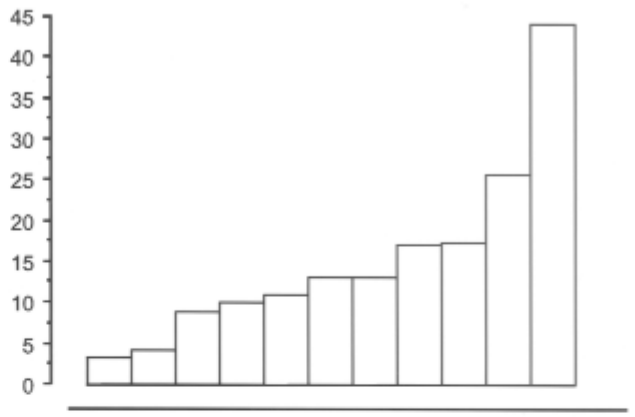

changes in SCBF, ${ }^{17,18}$ as occur during transient SCI. For our experiment, it was crucial to have immediate feedback to achieve the targeted flow reductions. Several drawbacks of the LDF technique have been described. Blood accumulation around the probe tip can underestimate the flow signal, and the technique is very sensitive to movement artifacts. We prevented excessive movement caused by transcranial stimulation with partial neuromuscular blockade. In addition, LDF provides only relative values of tissue blood flow. Nonetheless, a strong correlation exists between SCBF measured with radiolabeled microspheres and LDF. ${ }^{19}$ LDF probes were placed on the intact dura to decrease the possibility of traumatic neuronal tissue dam-
Figure 3. Individual values of laser-Doppler SCBF (Id_SCBF) and times until loss of lower-limb tcMEP signal during lumbar and thoracic SCI. Animals are ranked according to these times. In animals indicated by arrows, thoracic SCI was induced first, followed by lumbar SCI. Closed bars representing relative laser-Doppler SCBF values in the (hemic segment are superimposed on the open bars representing relative laser-Doppler SCBF values in the nonischemic segment. $A$ and $B$, Animals in which target levels in ischemic segment during lumbar SCI were not reached.

age during the tcMEP stimulations. With the application of this technique, SCBF and cerebral blood flow has been reliably assessed in swine. ${ }^{20,21}$ Placement of the probes on the intact dura has the possible disadvantage that the optical characteristics of the tissue between the probe and the spinal cord might influence the Doppler signal. However, this seems unlikely because the dura is translucent and contains very few vessels. ${ }^{22}$ Furthermore, LDF measures up to $1 \mathrm{~mm}$ in depth, ${ }^{23}$ and the thickness of the porcine dura is not more than $0.1 \mathrm{~mm} .{ }^{24}$ In a recent study, signals derived from intracerebral and epidural LDF probes showed similar values in a porcine model for hemorrhagic hypotension. ${ }^{25}$ Thus, in the present study the relative laser-Doppler SCBF 
values provided real-time evaluation of blood flow in the ventral portion of the spinal cord that contains the corticospinal motor pathways.

Loss of tcMEP responses was defined as a reduction of tcMEP amplitude to less than $25 \%$ of the baseline value. In general, the criterion for SCI during somatosensory evoked potentials monitoring is a decrease of amplitude to less than $50 \%$ of baseline or a $10 \%$ latency increase. ${ }^{26}$ The more restrictive criterion for spinal cord dysfunction during tcMEP monitoring was based on the larger amplitude variability of tcMEP signals compared with somatosensory evoked potentials. ${ }^{27}$ In the present study a closed-loop infusion system provided partial neuromuscular blockade, which may have contributed to the observed amplitude variability of the tcMEP signals. Partial muscle relaxation balances the surgical considerations of patient immobility and movements after transcranial stimulation and the minimal requirements for myogenic evoked potentials recording. ${ }^{28,29}$

\section{Gray-Matter Versus White-Matter Ischemia}

The present results are consistent with studies reporting that (poly)synaptic transmission is more sensitive to ischemia than axonal transmission. ${ }^{30,31}$ In general, the sensitivity of synaptic versus axonal transmission to ischemia correlates with the vulnerability of these structures to irreversible ischemic damage. Local differences in $\mathrm{Po}_{2}$ profiles and SCBF are thought to render motoneurons less resistant to ischemia than white matter, ${ }^{32}$ and histologic evaluation of spinal cord structures after transient ischemia showed a relative sparing of white matter. ${ }^{33}$ However, SCI induced by clamping of the thoracic aorta can result in axonal damage confined to the pyramidal tracts. $^{9,10}$ Furthermore, the similarities between myelinated axons and neurons with respect to ischemic injury processes indicate that white matter is vulnerable to ischemic injury. ${ }^{11,34}$ Thus, the axonal conductive properties appear to be relatively more resistant to ischemia, which may hamper early detection of impending white-matter injury.

These observations in the pig model may have clinical relevance for surgical procedures, such as repair of thoracoabdominal aneurysms, during which evoked potentials are applied for detection of SCI. Ideally, these techniques should detect the onset of ischemia before irreversible neuronal damage has occurred. In a recent study we observed delayed loss of tcMEP signals after clamping of a thoracic segment in 3 patients. ${ }^{2}$ If applicable to the human condition, the present data emphasize that thoracic SCI might occur even when the tcMEP signals remain present for 10 to 15 minutes in these procedures.

\section{Conclusion}

The results of this study indicate that in pigs a large bloodflow reduction that is limited to the lumbar spinal cord invariably results in rapid loss of tcMEP signals because of synaptic failure. In contrast, lower-limb tcMEP respond relatively late to blood flow reduction that is confined to the thoracic spinal cord. This finding might have implications for the interpretation of tcMEP during procedures in which the spinal cord is at risk for ischemia.

We thank Marjolein Porsius (Department of Anesthesiology) for monitoring of tcMEP, Marloes Klein and John Dries (Department of Experimental Surgery) for surgical assistance, Dirk Th. Ubbink and Jurgen de Graaff (Department of Surgery) for laser Doppler Flowmetry assistance, and all persons are located at the Academic Medical Center, University of Amsterdam, The Netherlands.

\section{References}

1. Dawson EG, Sherman JE, Kanim LE, Nuwer MR. Spinal cord monitoring. Results of the Scoliosis Research Society and the European Spinal Deformity Society survey. Spine. 1991;16:S361-4.

2. Meylaerts SA, Jacobs MJ, van Iterson V, De Haan P, Kalkman CJ. Comparison of transcranial motor evoked potentials and somatosensory evoked potentials during thoracoabdominal aortic aneurysm repair. Ann Surg. 1999;230:742-9.

3. Kalkman CJ, Been HD, Ongerboer de Visser BW. Intraoperative monitoring of spinal cord function: a review. Acta Orthop Scand. 1993; 64:114-23.

4. Tabaraud F, Boulesteix JM, Moulies D, Longis B, Lansade A, Terrier $\mathrm{G}$, et al. Monitoring of the motor pathway during spinal surgery. Spine. 1993;18:546-50.

5. de Haan P, Kalkman CJ, Ubags LH, Jacobs MJ, Drummond JC. A comparison of the sensitivity of epidural and myogenic transcranial motor-evoked responses in the detection of acute spinal cord ischemia in the rabbit. Anesth Analg. 1996;83:1022-7.

6. Machida M, Yamada T, Ross M, Kimura J, Hitchon P. Effect of spinal cord ischemia on compound muscle action potentials and spinal evoked potentials following spinal cord stimulation in the dog. $J$ Spinal Disord. 1990;3:345-52.

7. Kraus KH, Pope ER, O'Brien D, Hay BL. The effects of aortic occlusion on transcranially induced evoked potentials in the dog. Vet Surg. 1990;19:341-7.

8. Kobrine AI, Evans DE, Rizzoli HV. Effects of progressive hypoxia on long tract neural conduction in the spinal cord. Neurosurgery. 1980;7:369-75.

9. Blisard KS, Follis F, Wong R, Miller KB, Wernly JA, Scremin OU. Degeneration of axons in the corticospinal tract secondary to spinal cord ischemia in rats. Paraplegia. 1995;33:136-40.

10. Follis F, Scremin OU, Blisard KS, Scremin AM, Pett SB, Scott WJ, et al. Selective vulnerability of white matter during spinal cord ischemia. J Cereb Blood Flow Metab. 1993;13:170-8.

11. Pantoni L, Garcia JH, Gutierrez JA. Cerebral white matter is highly vulnerable to ischemia. Stroke. 1996;27:1641-7.

12. Kalkman CJ. LabVIEW: a software system for data acquisition, data analysis, and instrument control. J Clin Monit. 1995;11:51-8.

13. Kaplan BJ, Friedman WA, Gravenstein N, Rich R, Davis RF. Effects of aortic occlusion on regional spinal cord blood flow and somatosensory evoked potentials in sheep. Neurosurgery. 1987;21:668-75.

14. Kolenda H, Steffens H, Hagenah J, Diegeler A, Ankorina I, Schomburg ED. Influence of short-term ischemia on segmental spinal cord reflex functions in cats. J Spinal Disord. 1997;10:68-79.

15. Wissdorf H. Die Gefässversorgung der Wirbelsäule und des Rückenmarckes vom Hausschwein. 1970. p. 73-96.

16. Dommisse GF. The blood supply of the spinal cord. A critical vascular zone in spinal surgery. J Bone Joint Surg. 1974;56:225-35.

17. Marsala M, Sorkin LS, Yaksh TL. Transient spinal ischemia in rat: characterization of spinal cord blood flow, extracellular amino acid release, and concurrent histopathological damage. J Cereb Blood Flow Metab. 1994;14:604-14. 
18. Yamada T, Morimoto T, Nakase H, Hirabayashi H, Hiramatsu K, Sakaki T. Spinal cord blood flow and pathophysiological changes after transient spinal cord ischemia in cats. Neurosurgery. 1998;42:626-34.

19. Lindsberg PJ, O’Neill JT, Paakkari IA, Hallenbeck JM, Feuerstein G Validation of laser-Doppler flowmetry in measurement of spinal cord blood flow. Am J Physiol. 1989;257:H674-80.

20. Christiansson L, Hellberg A, Koga I, Thelin S, Bergqvist D, Wiklund $\mathrm{L}$, et al. A new method of intrathecal PO2, PCO2, and pH measurements for continuous monitoring of spinal cord ischemia during thoracic aortic clamping in pigs. Surgery. 2000;127:571-6.

21. Nozari A, Rubertsson S, Wiklund L. Intra-aortic administration of epinephrine above an aortic balloon occlusion during experimental CPR does not further improve cerebral blood flow and oxygenation. Resuscitation. 2000;44:119-27.

22. Frerichs KU, Feuerstein GZ. Laser-Doppler flowmetry. A review of its application for measuring cerebral and spinal cord blood flow. Mol Chem Neuropathol. 1990;12:55-70.

23. Nilsson GE, Tenland T, Obert PA. A new instrument for continuous measurement of tissue blood flow by light beating spectroscopy. IEEE Trans Biomed Eng. 1980;27:12-9.

24. Orlin JR, Osen KK, Hovig T. Subdural compartment in pig: a morphologic study with blood and horseradish peroxidase infused subdurally. Anat Rec. 1991;230:22-37.

25. Rise IR, Risoe C, Kirkeby OJ. Cerebrovascular effects of high intracranial pressure after moderate hemorrhage. J Neurosurg Anesthesiol. 1998;10:224-30.

26. Brown RH, Nash CL, Berilla JA, Amaddio MD. Cortical evoked potential monitoring: a system for intraoperative monitoring of spinal cord function. Spine. 1984;9:256-61.
27. de Haan P, Kalkman CJ, de Mol BA, Ubags LH, Veldman DJ, Jacobs MJ. Efficacy of transcranial motor-evoked myogenic potentials to detect spinal cord ischemia during operations for thoracoabdominal aneurysms. J Thorac Cardiovasc Surg. 1997;113:87-100.

28. Stinson LW Jr, Murray MJ, Jones KA, Assef SJ, Burke MJ, Behrens TL, et al. A computer-controlled, closed-loop infusion system for infusing muscle relaxants: its use during motor-evoked potential monitoring. J Cardiothorac Vasc Anesth. 1994;8:40-4.

29. Adams DC, Emerson RG, Heyer EJ, McCormick PC, Carmel PW, Stein BM, et al. Monitoring of intraoperative motor-evoked potentials under conditions of controlled neuromuscular blockade. Anesth Analg. 1993;77:913-8.

30. Konrad PE, Tacker WA, Levy WJ, Reedy DP, Cook JR, Geddes LA. Motor evoked potentials in the dog: effects of global ischemia on spinal cord and peripheral nerve signals. Neurosurgery. 1987;20:11724.

31. Laschinger JC, Owen J, Rosenbloom M, Cox JL, Kouchoukos NT. Direct noninvasive monitoring of spinal cord motor function during thoracic aortic occlusion: use of motor evoked potentials. J Vasc Surg. 1988;7:161-71.

32. Hayashi N, Green BA, Gonzalez-Carvajal M, Mora J, Veraa RP. Local blood flow, oxygen tension, and oxygen consumption in the rat spinal cord. Part 2. Relation to segmental level. J Neurosurg. 1983;58:52630 .

33. DeGirolami U, Zivin JA. Neuropathology of experimental spinal cord ischemia in the rabbit. J Neuropathol Exp Neurol. 1982;41:129-49.

34. Stys PK. Anoxic and ischemic injury of myelinated axons in CNS white matter: from mechanistic concepts to therapeutics. J Cereb Blood Flow Metab. 1998;18:2-25. 